\title{
A STUDY ON THE WEAR BEHAVIOUR OF MONOLITHIC MULLITE MATERIALS FOR DENTAL APPLICATIONS
}

\author{
Perent GÜLER ${ }^{1}$, Burcu ERTUĞ ${ }^{1}$, Nazenin İPEK IŞIKÇI ${ }^{1}$, \\ Alpagut KARA ${ }^{2}$ \\ ${ }^{1}$ Nişantaşı University, Faculty of Engineering and Architecture, Istanbul, Turkey, \\ ${ }^{2}$ Eskişehir Technical University, Department of Materials Science and Engineering, Eskişehir, Turkey \\ e-mail: burcu.ertug@nisantasi.edu.tr
}

\begin{abstract}
The aim of this study is to evaluate the potential use of the monolithic mullite samples for the dental applications. For this purpose, at first the monolithic mullite samples obtained by the powder metallurgy method have been characterized by the scanning electron microscopy (SEM) together with the EDS analysis. The pin-ondisk tribometer has been used to conduct the wear test in order to determine the volumetric loss. After the wear tests, the worn surfaces of the sintered mullite samples have been studied. The presence of the $3 \mathrm{Al}_{2} \mathrm{O}_{3} .2 \mathrm{SiO}_{2}$ structure has been confirmed by the FT-IR spectroscopy through the observation of the characteristic Al-O-Si linkages at the spectra. The wear rate results derived from the volumetric losses have been measured to be around $2.42 \times 10^{-6} \mathrm{~mm}^{3} / \mathrm{Nm}$. This value has been found to be lower than those of alumina and alumina-mullite composites in the previous studies, which explains the higher wear resistance of these mullite materials. The room temperature friction coefficients of AS-1 and AS-2 samples have been determined to be 0.88 and 0.80 , respectively. The wear behaviour of the samples has been correlated to the sintering temperature and the resultant relative density of the samples. The mullite samples obtained in this study have indicated better wear performance than the other materials (alumina and alumina-mullite composites) in spite of the usage of monolithic material. Therefore, this study suggests that the monolithic mullite materials have a potential to be exploited for the replacement of the previous ceramic-based dental materials. Further studies might contribute to the improvement of these materials to be utilized in the oral environment.
\end{abstract}

KEYWORDS: wear, mullite, dental material, implant

\section{Introduction}

Dental crowns are typically made out of porcelain veneer and alumina core. A three-layer dental structure with porcelain-mullite-alumina was produced against the risk of fracture [1]. Mullite is still an attractive material for its optical properties, such as adequate transparency. Mullite products are conventionally-processed by a shape-forming step followed by the sintering. A solid-solid reaction or a transient liquid-phase reaction can produce the mullitization process through the interdiffusion of the present atoms. The mullitization is carried out around $1600{ }^{\circ} \mathrm{C}$ during solid-state reaction [2-4]. For load bearing dental implants, poor fracture toughness is a weakening property which is the driving factor for the improvement of the dental ceramics $[5,6]$.

High-purity precursors are not preferred for the production of mullite ceramics for the dentistry applications due to their high costs. Instead, abundant raw materials of alumina and silica are subjected to reaction sintering to produce mullite samples with satisfactory mechanical properties at a low cost [7]. Mullite is among the oxides used for advanced ceramics with variety of optical, thermal and mechanical (strength, toughness etc) properties [8]. Besides, it exhibits some attractive properties for the field of dental implants such as thermal expansion coefficient, environmental durability.

The densification of mullite and alumina was accomplished using the additives such as $\mathrm{La}_{2} \mathrm{O}_{3}, \mathrm{~B}_{2} \mathrm{O}_{3}$ 
and the final mechanical properties were improved. Also, with the addition of $\mathrm{Y}_{2} \mathrm{O}_{3}$, a full density was achieved together with mullitization [9-13]. A number of these methods have a potential to produce denser dental implants that might exhibit better mechanical performance. In addition, by studying the wear properties of the dental ceramics, a better understanding of the interacting surfaces might be facilitated in the oral environment [14].

In this study, single-stage sintering has been applied to produce dense mullite ceramics. The microstructures, and the wear properties of mullitebased dental materials have been investigated.

\section{Materials and methods}

In the present study, the mullite samples $3 \mathrm{Al}_{2} \mathrm{O}_{3} \cdot 2 \mathrm{SiO}_{2}$ have been prepared in a stoichiometric ratio. The sample preparation has been done by powder metallurgy using the raw powders of $\mathrm{SiO}_{2}$ and $\mathrm{Al}_{2} \mathrm{O}_{3}$ after the milling in a planetary ball mill [15] for 1-3 hours, the calcined powder has been compressed to obtain the disc samples. Then, the samples have been sintered at $1670{ }^{\circ} \mathrm{C}$ and $1700{ }^{\circ} \mathrm{C}$ for a dwell time of $180 \mathrm{~min}$ as described in detail in our previous study [16].

Fourier Transform Infrared Spectroscopy (ATRFTIR) analysis (Perkin-Elmer) has been carried out at ambient temperature in the spectrum range of 4000$400 \mathrm{~cm}^{-1}$ for the qualitative analysis on the chemical bonding. Au-Pd coating unit has been utilized prior to the microstructural characterization by means of SEM (Scanning Electron Microscope), using Jeol-JSM6060 equipped with Energy Dispersive Spectrometer (EDS).
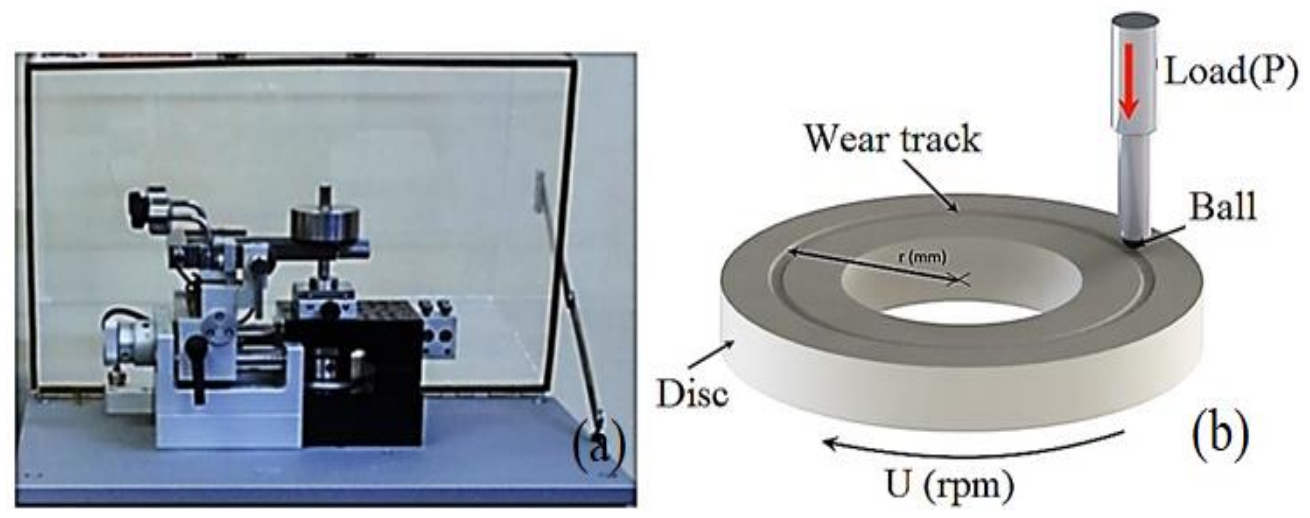

Fig. 1. (a) Tribometer set-up and (b) design of pin-on-disk test according to ASTM-G99 [17]

The wear tests have been carried out using the tribometer set-up in Figure 1(a) (CSM Instruments). The tribometer is a pin-on-disk type set-up which applies a load of $10 \mathrm{~N}$ at a speed of $0.15 \mathrm{~m} / \mathrm{s}$. The test distance was $200 \mathrm{~m}$ and the wear test was conducted against $\mathrm{Al}_{2} \mathrm{O}_{3}$ balls as the counterpart under unlubricated wear conditions. The volumetric wear loss values for the samples AS-1 and AS-2 have been determined in cubic millimetres. After the wear test, the wear rates of the mullite samples have been calculated by Eq.1 as described in [18, 19].

$$
\mathrm{W}_{\mathrm{V}(\mathrm{disc})}=\mathrm{V}_{\mathrm{disc}} / \mathrm{F}_{\mathrm{N}} \cdot \mathrm{L}
$$

where $\mathrm{W}_{\mathrm{V}}$ is the disc wear rate $\left(\mathrm{mm}^{3} / \mathrm{Nm}\right), \mathrm{V}_{\text {disc }}$ is the wear volume $\left(\mathrm{mm}^{3}\right), \mathrm{F}_{\mathrm{N}}$-load $(\mathrm{N}), \mathrm{L}$ sliding distance $(\mathrm{m})$.

\section{Results}

According to FTIR results, as the sintering temperature changed from $1670{ }^{\circ} \mathrm{C}$ to $1700{ }^{\circ} \mathrm{C}$, the intensities of the FTIR bands increased. Mullite is a structure of parallel chains where edge-sharing $\mathrm{MO}_{6}$ octahedra is cross-linked with $\mathrm{TO}_{4}$ tetrahedra [8] and at the spectra in Fig. 2 and Fig. 3, the wide bands at $3448 \mathrm{~cm}^{-1}$ and at $3450 \mathrm{~cm}^{-1}$ can be associated with the stretch vibration of $\mathrm{OH}$ for AS-1 and AS-2, respectively similar to those of the silicates. The stretch vibration of $\mathrm{OH}$ in $\mathrm{Si}-\mathrm{OH}$ groups has also been observed at $3748 \mathrm{~cm}^{-1}$. The bands observed at around $1150 \mathrm{~cm}^{-1}$ in Fig. 2 and Fig. 3 might be related to vibrational mode of asymmetric stretching of Si-O$\mathrm{Si}$ and the peaks at $1137 \mathrm{~cm}^{-1}$ and $1140 \mathrm{~cm}^{-1}$ in any of the graphs which might be related to $\mathrm{SiO}_{4}$.

Since 3/2-mullite with its formula $\mathrm{Al}_{2}\left(\mathrm{Al}_{2+2 x} \mathrm{Si}_{2-2 x}\right) \mathrm{O}_{10-x}$ is an orthorhombic aluminosilicate (where $x$ is 0.25) [8], the peaks observed at $755 \mathrm{~cm}^{-1}$ and $750 \mathrm{~cm}^{-1}$ are attributed to (Si,Al)-O-(Si,Al) bending mode for $\mathrm{AS}-1$ and $\mathrm{AS}-2$ samples, respectively in the mullite structure. The deformation vibration of the adsorbed water has been observed at around $1600 \mathrm{~cm}^{-1}$ [20].

Mullite microstructures have been given in Fig. 4 with the relevant EDS analysis results. EDS results 
have indicated that the compositions are close to the mullite solid solution in the binary phase diagram. Also, the relative sintered densities have been measured to be $86-98 \%$ and the equiaxed grain morphology has been observed with grain size values of 2.5-4 $\mu \mathrm{m}$ in our previous study [16].

For AS-1 sample, the wear rate has been measured to be $2.42 \times 10^{-6} \mathrm{~mm}^{3} / \mathrm{Nm}$ as it can be seen in Fig. 5. For comparison, the wear rate of alumina was determined to be $6.76 \times 10^{-5}-1.66 \times 10^{-4} \mathrm{~mm}^{3} / \mathrm{Nm}$ whereas that of alumina and mullite binary composites were $4.6 \times 10^{-5}-1.3 \times 10^{-4} \mathrm{~mm}^{3} / \mathrm{Nm}$. The friction coefficient of alumina and mullite binary composites were found to be lower, which results in a higher wear resistance of these composites with the co-working of both fracture and plastic wear mechanisms [21].

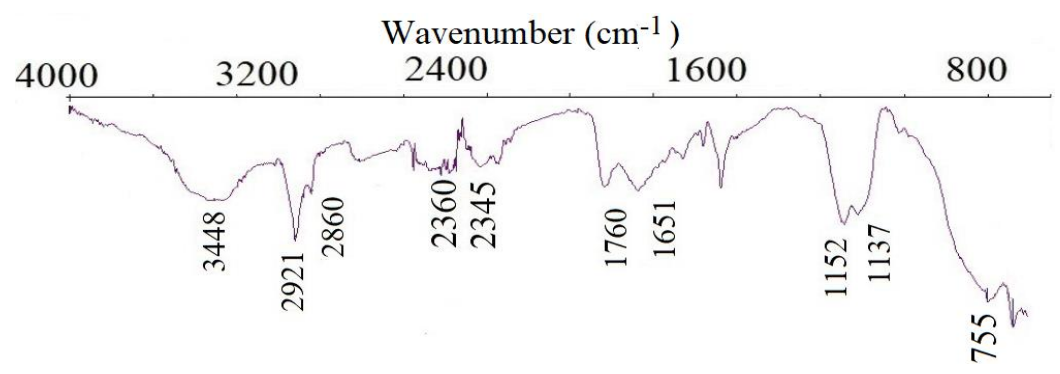

Fig. 2. FTIR spectrum of AS-1 within $800-4000 \mathrm{~cm}^{-1}$ after heat treating

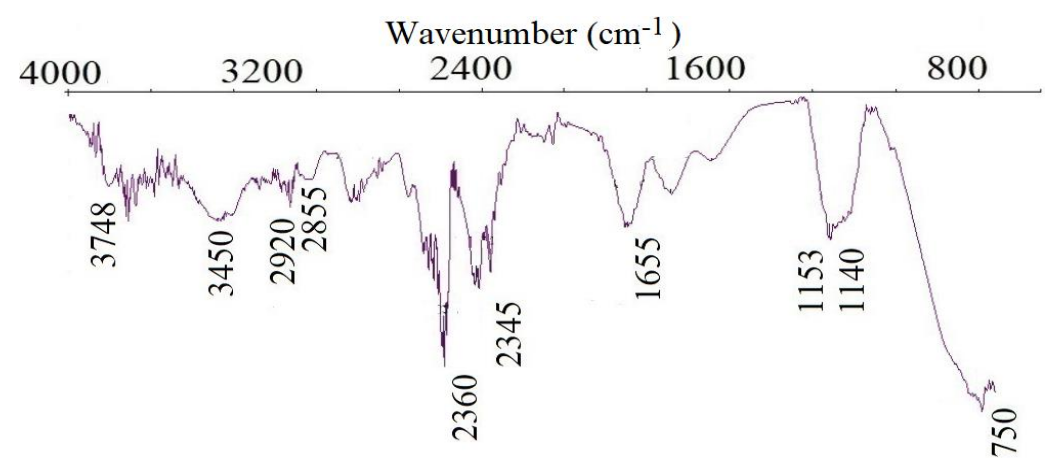

Fig. 3 FTIR spectrum of AS-2 within $800-4000 \mathrm{~cm}^{-1}$ after heat treating

The friction coefficients of AS-1 and AS-2 samples have been measured to be 0.88 and 0.80 , respectively. For some of the different mullite compositions, friction coefficients were found to be 0.75-0.9 [22]. A number of researchers investigated the wear behavior of the mullite-based materials using various temperatures [23]. The room temperature friction coefficient was measured to be $0.75-0.90$, rising up to 1.0 with the temperature. The wear rate values were found to be $7 \times 10^{-4} \mathrm{~mm}^{3} / \mathrm{Nm}$ and $3.5 \times 10^{-5} \mathrm{~mm}^{3} / \mathrm{Nm}$ for mullite and alumina materials, respectively [22].

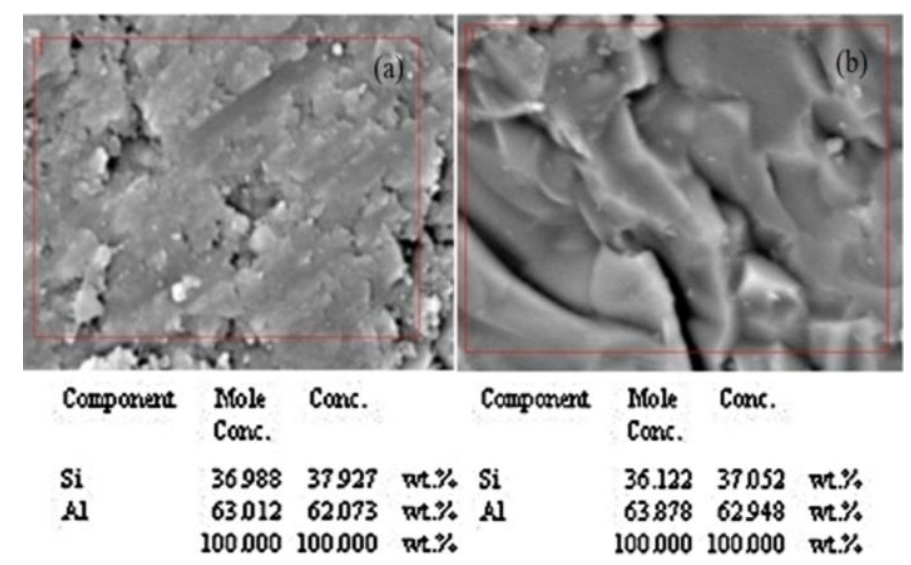

Fig. 4. SEM-EDS analysis of (a) AS-1 and (b) AS-2 


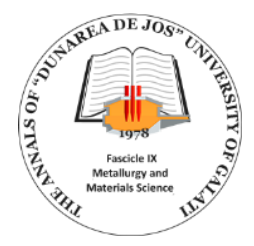

THE ANNALS OF "DUNAREA DE JOS" UNIVERSITY OF GALATI

FASCICLE IX. METALLURGY AND MATERIALS SCIENCE

No. 3 - 2021, ISSN 2668-4748; e-ISSN 2668-4756

Article DOI: $\underline{\text { https://doi.org/10.35219/mms.2021.3.02 }}$
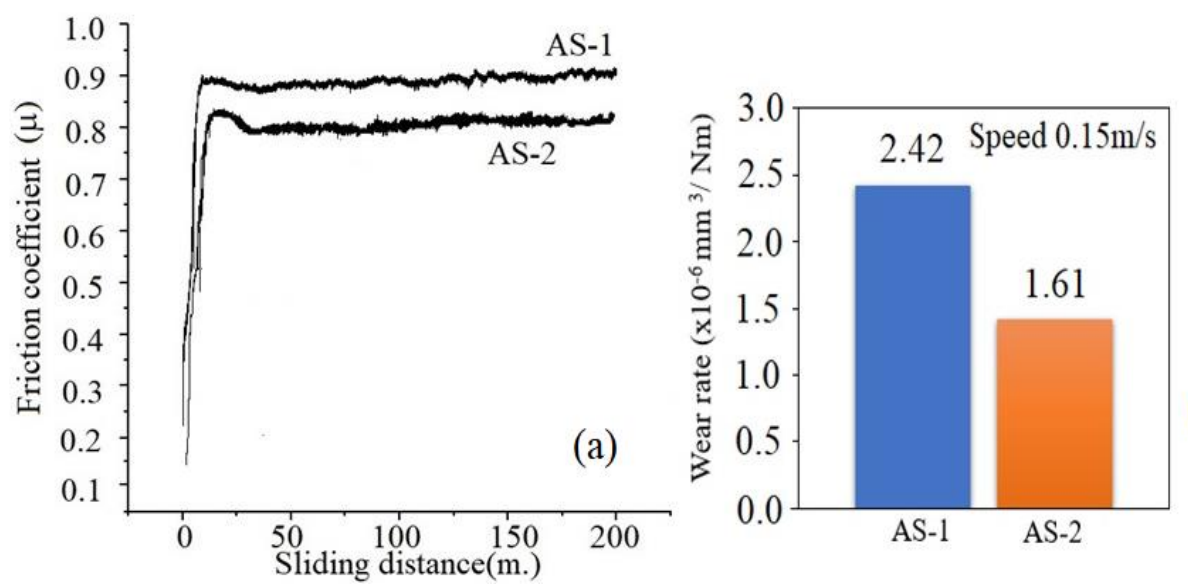

(b)

Fig. 5. (a) Plot of friction coefficient vs. sliding distance and (b) wear rate values under $10 \mathrm{~N}$ for AS- 1 and AS-2 against alumina
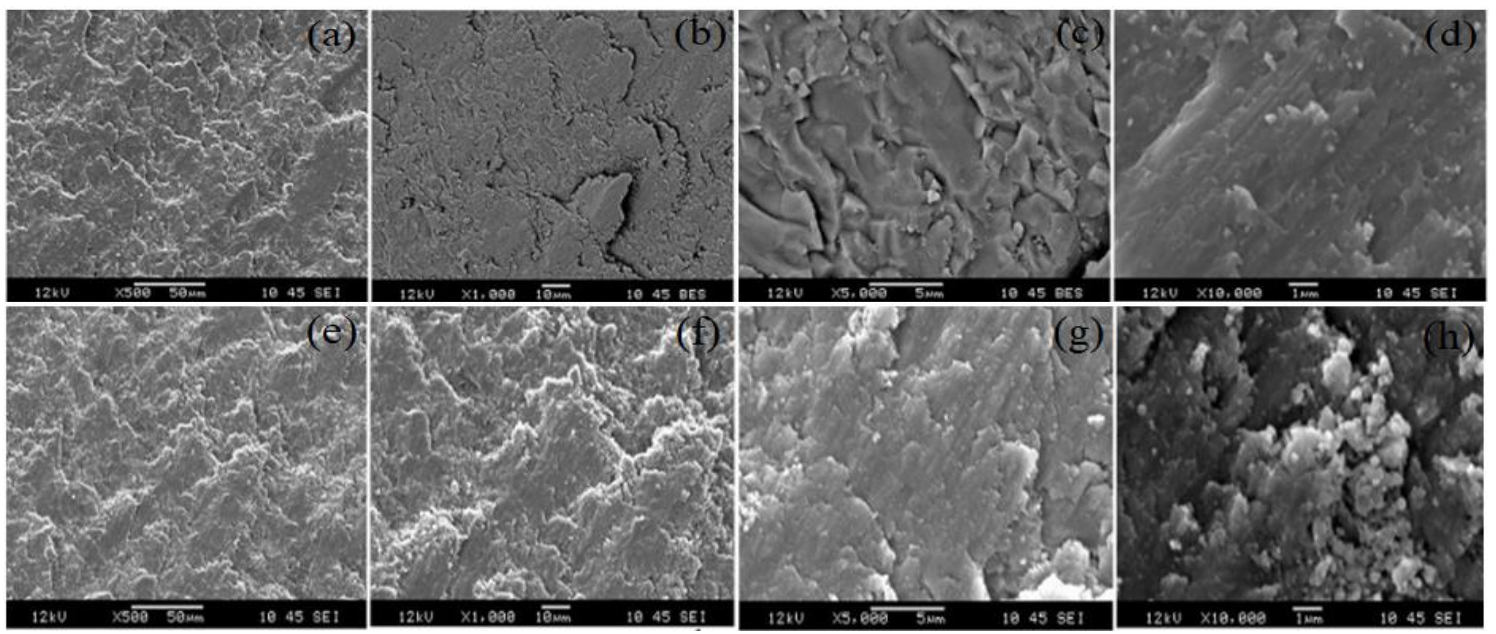

Fig. 6. The worn surfaces after the wear test of the samples (a) AS-1 and (b) AS-2

Following the wear test, worn surfaces of the two samples have been examined by SEM and the images have been given in Fig. 6. After the dry wear test of $\mathrm{Al}_{2} \mathrm{O}_{3}$-based materials, the repeated strips were observed on the worn surfaces perpendicular to sliding direction [24]. Also, the smooth regions were observed in the case of plastic deformation and the brittle fracture resulted in the pull-out of the material on the worn surface [18]. The wear rate values of the monolithic mullite samples have been found to be twenty-five times lower than the monolithic alumina materials and twenty times lower than aluminamullite composites, showing a higher wear resistance.

The mullite phase peak intensity in the XRD pattern rises with the sintering temperature as a result of densification and the full mullitization [16]. This high wear resistance has been found to be related to the higher hardness and the densification of $98 \%$ due to sintering at $1700{ }^{\circ} \mathrm{C}$. In addition, the uniform crystalline microstructure as described in [25] in these monolithic mullite samples has resulted in a high wear resistance.

\section{Conclusions}

This work presents the wear behavior of the monolithic mullite-based dental materials depending on the sintering temperature. FT-IR analysis observations have showed the characteristic Al-O-Si linkages confirming the presence of $3 \mathrm{Al}_{2} \mathrm{O}_{3} \cdot 2 \mathrm{SiO}_{2}$ structure. Under test load of $10 \mathrm{~N}$, the sintering at $1700{ }^{\circ} \mathrm{C}$ has yielded a higher friction coefficient. The increase in the sintering temperature has resulted in denser mullite samples and in the improvement of the relevant wear behavior. The wear rate values of the sintered dental materials have been measured to be twenty or twenty-five times lower by comparing the results of the previously-known materials from the literature, indicating a better wear performance. This high wear resistance might be explained by higher 


\section{THE ANNALS OF “DUNAREA DE JOS” UNIVERSITY OF GALATI \\ FASCICLE IX. METALLURGY AND MATERIALS SCIENCE \\ $\mathrm{N}^{\circ} .3$ - 2021, ISSN 2668-4748; e-ISSN 2668-4756 \\ Article DOI: https://doi.org/10.35219/mms.2021.3.02}

densification, uniform crystalline microstructure and hardness. Further studies regarding the chemical durability tests of these materials might contribute to our knowledge on their behavior in the oral environment.

\section{Acknowledgments}

The authors are grateful to Metallurgical Engineer Haluk Gürses who provided the expertise for the microstructural analysis, FTIR spectroscopy and wear tests from Dokuz Eylul University, Industrial Services, Buca, Izmir.

\section{References}

[1]. Jang H. J., Park D. H., Jung Y. G., Lee H., Microstructural design and evaluation of porcelain/mullite/alumina layered structure for dental application, MRS OPL, 820, 2004.

[2]. Souto P. M., Menezes R. R., Kiminami R., Sintering of commercial mullite powder: Effect of $\mathrm{MgO}$ dopant, J Mater Process Tech, 209 (1), p. 548-553, 2009.

[3]. Viswabaskaran V., Gnanam F. D., Balasubramanian M., Mullitisation behaviour of South Indian clays, Ceram. Int., 28(5), p. 557-564, 2002.

[4]. Dong Y., Feng X., Ding Y., Liu X., Meng G., Preparation of low-cost mullite ceramics from natural bauxite and industrial waste fly ash, J Alloy Compd, 460(1), p. 599-606, 2008

[5]. Lakshmi R., Sasikumar S., Influence of needle-like morphology on the bioactivity of nanocrystalline wollastonite-an in vitro study, Int J Nanomed, 10, p. 129-136, 2015.

[6]. Shirazi F. S., Mehrali M., Oshkoura A. A., Metselaara H. S. C., Kadri N. A., Abu Osman N. A., Mechanical and physical properties of calcium silicate/alumina composite for biomedical engineering applications, J Mech Behav Biomed, 30, p. 168-175, 2014.

[7]. Tripathi H. S., Ghosh A., Halder M. K., Mukherjee B., Maiti H. S., Microstructure and properties of sintered mullite developed from Indian bauxite, B Mater Sci, 35(4), p. 639-643, 2012.

[8]. Schneider H., Fischer R. X., Schreuer J., Mullite: Crystal structure and related properties, J Am Ceram Soc., 98(10), p. 2948-2967, 2015.

[9]. Fathi H. M., Johnson A., The effect of $\mathrm{TiO}_{2}$ concentration on properties of apatite-mullite glass-ceramics for dental use, Dent. Mater., 32(2), p. 311-322, 2016.
[10]. Rahimi S., SharifianJazi F., Esmaeilkhanian A., Moradi M., Samghabadi A. H., Effect of $\mathrm{SiO}_{2}$ content on $\mathrm{Y}$-TZP/Al $\mathrm{Al}_{2} \mathrm{O}_{3}$ ceramic-nanocomposite properties as potential dental applications, Ceram. Int., 46(8), Part A, p. 10910-10916, 2020.

[11]. Cestari A., Sol-gel methods for synthesis of aluminosilicates for dental applications, J Dent., 55, p. 105-113, 2016.

[12]. She J., Mechnich P., Schmücker M., Schneider H., Lowtemperature reaction-sintering of mullite ceramics with an $Y O$ Addition, Ceram. Int., 27(8), p. 847-852, 2001.

[13]. Mollazadeh S., Javadpour J., Eftekhari Yekta B., Jafarzadeh T. S., Youssefi A., Synthesis and characterisation of dental composite materials reinforced with fluoroapatite-mullite glass-ceramic particles, Adv Appl Ceram, 112(5), p. 294-300, 2013.

[14]. Basu B., Kalin M., Tribology of ceramics and composites: A materials science perspective, John Wiley \& Sons, 2011.

[15]. ***, MTI Corporation, https://www.mtixtl.com/MSK-SFM-13.aspx.

[16]. Şahin M., Güler P., Güzel K., Ertuğ B., Kara A., Influence of the mechanical alloying duration on the sintering of mullite ceramics, IMSTEC18, Nevsehir, September 17-19, 2018.

[17]. Miramontes J. C., Tiburcio C. G., Tellez A. V., Salas C. P., Calderón F. A., Wear resistance of thermal spray WC-Co-VC nanostructured coatings, Advances in Tribology, IntechOpen, Croatia, p. 51-65, 2016.

[18]. Zhang F. C., Luo H. H., Wang T. S., Roberts S. G., Todd R. I., Influence factors on wear resistance of two alumina matrix composites, Wear, 265(1-2), p. 27-33, 2008.

[19]. Sulima I., Tribological properties of steel/TiB 2 composites prepared by spark plasma sintering, Arch Metall Mater, 59(4), p. 1263-1268, 2014.

[20]. Gören R., Ersoy B., Ozgur C., Alp T., Colloidal stabilityslip casting behavior relationship in slurry of mullite synthesized by the USP method, Ceram. Int., 38, p. 679-685, 2012.

[21]. Luo H. H., Zhang F. C., Roberts S. G., Wear resistance of reaction sintered alumina/mullite composites, Mater Sci Eng, 478(1-2), p. 270-275, 2008.

[22]. Schneider H., Komarneni S., Mullite, John Wiley \& Sons, 2005.

[23]. Nishikawa T., Kawabe K., Takatsu M., Kamiya H., Sliding wear properties of sintered mullite ceramics, J Ceram Soc Jpn, 100(1163), p. 912-917, 1992.

[24]. Taktak S., Baspinar M. S., Wear and friction behaviour of alumina/mullite composite by sol-gel infiltration technique, Mater Design, 26(5), p. 459-464, 2005.

[25]. Medvedovski E., Alumina-mullite ceramics for structural applications, Ceram. Int., 32(4), p. 369-375, 2006. 